\title{
Differentiation Capability Evaluation of Osteoblast by Functionalized DLC Thin Films with Plasma Processing
}

\author{
Keishi Okamoto $^{\dagger * *}$, Tatsuyuki Nakatani, Yuki Nitta, \\ Seicho Makihira*, Satoshi Iwata*, Hiroki Nikawa* and Takayuki Takahagi** \\ ${ }^{\dagger}$ Toyo Advanced Technologies Co. , Ltd. \\ 5-3-38 Ujina-higashi, Minami-ku, Hiroshima 734-8501, Japan \\ * Graduate School of Biomedical Sciences Hiroshima University \\ 1-2-3 Kasumi, Minami-ku, Hiroshima 734-8553, Japan \\ ** Graduate School of Advanced Sciences of Matter Hiroshima University \\ 1-3-1 Kagamiyama, Higashi-Hiroshima, Hiroshima, 739-8530, Japan \\ nakatani.t@toyo-at.co.jp
}

\section{Keywords: Diamond-like carbon, osteoblast, biocompatibility, dental implant}

\section{Introduction}

Diamond-like carbon (DLC) are widely used in industrial applications, such as automobile parts with high wear resistance $[1,2]$. Moreover, DLC has been considered as one of the excellent biocompatible coating materials for medical devices in recent years [3-13]. It is known that DLC has a wide composition in a material composed of $s p^{2}$ carbon, $s p^{3}$ carbon, and hydrogen. Moreover, a functional group can be introduced using the carbon bond of DLC. Then, we examined the functionality of DLC for dental implant surface treatment by plasma processing. Fig. 1 shows the model of the functional group introduction into the surface of DLC using by $\mathrm{O}_{2}$ and/or $\mathrm{NH}_{3}$ plasma. Radicals and ions are generated with plasma, and the functional group terminates the carbon bond of DLC [14]. This plasma processing can control the zeta potential within the wide range of -45

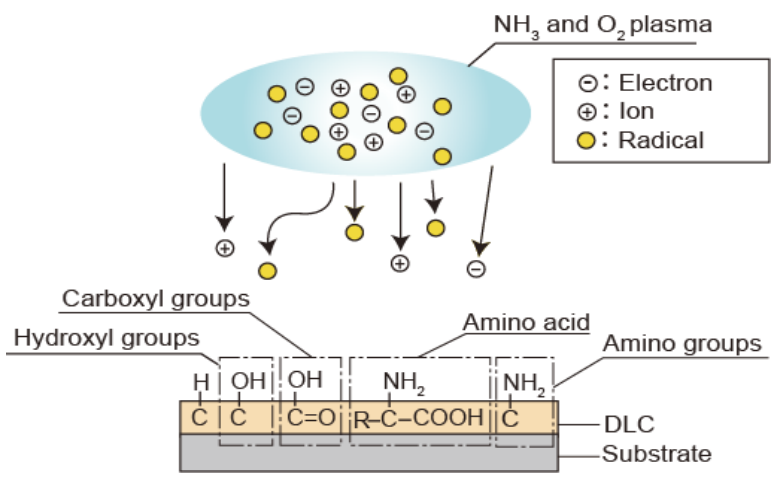

Fig.1 Schematic of DLC thin films surface with introduced functional groups. to $+10 \mathrm{mV}$ [15]. In addition, we report that the characteristics of platelet adhesion and fibrin coagulation can be controlled on the basis of the functional group introduction ratio and zeta potential [16]. The result showing blood compatibility suggests the possibility of applying to various implants that come in contact with blood.

Currently, various implants are applied by dental and orthopedic operations. The dental implant fixture often reduces infection and an inappropriate occlusal force because the period until fixture is long. Therefore, urgent requirements are to develop a technology that improves the growth of the bone and to complete a treatment in a short period. Moreover, platelet-rich plasma is known to act on the bone growth factor and to stimulate periodontal regeneration $[17,18]$. Therefore, we applied DLC used by controlling blood compatibility and aimed at the development of a technology that controlled the differentiation of osteoblast. In an actual experiment aimed at the functionalization of DLC to introduce a functional group into a surface by plasma surface treatment, we examined the effect of the differentiation capability of osteoblast.

\section{Experimental setup and conditions}

DLC coating used ionized-assisted deposition of the plasma-enhanced chemical vapor deposition method. The pressure of the chamber used was adjusted to $0.2 \mathrm{~Pa}$ using $\mathrm{C}_{6} \mathrm{H}_{6}$ as the operation gas. The electric power of the 


\begin{tabular}{ll}
\hline \hline Base pressure: & $1 \times 10^{-3} \mathrm{~Pa}$ \\
Operational pressure: & $4 \mathrm{~Pa}$ \\
RF power: & $100 \mathrm{~W}$ \\
Treatment time: & $15 \mathrm{~s}$ \\
Operational gas: & $\mathrm{O}_{2}, \mathrm{NH}_{3}$ \\
\hline \hline
\end{tabular}

Table 1 Surface treatment conditions by plasma.

filament was $300 \mathrm{~W}$, and the bias voltage of the substrate was $2 \mathrm{kV}$. The test piece material used the pure Ti (JIS TP340C).

Next, functional group modification was conducted on DLC surfaces using the plasma surface treatment technology, and the relationship between the composition of the surface and the composition ratio of functional groups introduced was examined. The equipment used was a capacitively coupled plasma surface treatment system with a radiofrequency power source. Table 1 shows the plasma surface treatment conditions used in this experiment.

DLC surface was analyzed by X-ray photoelectron spectroscopy (JOEL JPS9010) with non-monochromatized $\mathrm{AlK}_{\alpha}$ rays. The $\mathrm{C} 1 \mathrm{~s}$ spectrum was first assigned into four elements (C-C $s p^{3} \quad(283.8 \mathrm{eV}), \quad \mathrm{C}-\mathrm{C} s p^{2}$ $(284.3 \mathrm{eV}), \mathrm{C}-\mathrm{H} s p^{2}(284.8 \mathrm{eV})$, and $\mathrm{C}-\mathrm{H} s p^{3}$ $(285.3 \mathrm{eV}))$ [19-21]. Then, the $\mathrm{C} 1 \mathrm{~s}$ spectrum was analyzed so that the ratio of the total area of $\mathrm{C}-\mathrm{O}(\mathrm{O}-\mathrm{C}-\mathrm{O}), \mathrm{C}=\mathrm{O}(287.3 \mathrm{eV})$, and $\mathrm{O}=\mathrm{C}-\mathrm{O}$ $(288.8 \mathrm{eV})$, to the area of $\mathrm{C}-\mathrm{N}$ may be the same as the ratio of oxygen and nitrogen to carbon. The analysis of DLC was carried out by the angle resolved XPS method. Then, the emission angle was varied as 0 and $75^{\circ}$.

To examine the effect of DLC on osteoblast differentiation, osteoblastic cell line; MC3T3-E1 was used in the present study. MC3T3-E1 cell line was purchased from the European Collection of Cell Cultures (Wiltshire). MC3T3-E1 cells were cultured in alpha-MEM supplemented with an antibiotic mixture (Invitrogen), 10\% fetal bovine serum (Biological Industries) and $50 \mathrm{ug} / \mathrm{ml} \mathrm{L-ascorbic}$ acid (Sigma). MC3T3-E1 were maintained at $37^{\circ} \mathrm{C}$ under $5 \% \mathrm{CO}_{2} / 95 \%$ air for an experiment. The cells were seeded to the surfaces of $\mathrm{Ti}$ specimens placed on the bottoms of 24-well plates at a density of $5.0 \times 10^{4}$ cells/well titanium specimens and well was extracted using TRIzol reagent maintained for 7 days [22]. Total RNA of each well was extracted using TRIzol reagent (Invitrogen), and first-strand cDNA from total RNA (100 ng) using ReverTra
Ace reverse transcriptase (Toyobo). Real-time quantitative RT-PCR analysis for runt-related transcription factor 2 (Runx2), type I collagen and $\beta$-actin were performed using Colbet (Qiagen). $\beta$-actin was chosen as an internal control against which to standardize the variability in amplification owing to slight differences in starting total RNA concentrations. The sequences of the primers used in these analyses are previously described [23]. Differences between mean values of groups were subjected to a one-way analysis-ofvariance (ANOVA) and Tukey's multiple range test.

\section{Result and discussion}

Table 2 shows the atomicity ratios of functionalized DLC by plasma surface treatment for $\mathrm{C}, \mathrm{O}$, and $\mathrm{N}$. Then, the emission angle was $0^{\circ} \cdot \mathrm{O}_{2}$ plasma has increased the ratio of oxygen a little. Moreover, $\mathrm{NH}_{3}$ plasma introduced nitrogen.

\begin{tabular}{|l|l|c|c|c|}
\hline \multirow{2}{*}{} & \multicolumn{3}{|c|}{ atomicity ratio } \\
\cline { 2 - 5 } & $\mathrm{C}$ & $\mathrm{O}$ & $\mathrm{N}$ \\
\hline No.1 & DLC(Untreated) & 0.92 & 0.08 & $>0.003$ \\
\hline No.2 & $\mathrm{O}_{2}$ Plasma & 0.90 & 0.10 & $>0.002$ \\
\hline No.3 & $\mathrm{NH}_{3}$ Plasma & 0.86 & 0.04 & 0.10 \\
\hline
\end{tabular}

Table 2 Atomicity ratio of functionalized DLC by plasma surface treatment.

Fig. 2 shows the profile used to analyze the $\mathrm{C} 1 \mathrm{~s}$ spectra of untreated DLC by the angleresolved XPS method. The $\mathrm{C} 1 \mathrm{~s}$ spectra was analyzed and the bonds of $\mathrm{C}-\mathrm{O}(\mathrm{O}-\mathrm{C}-\mathrm{O}), \mathrm{C}=\mathrm{O}$, and $\mathrm{O}-\mathrm{C}=\mathrm{O}$ were fitted. It was shown by angleresolved XPS that many elements of $\mathrm{O}-\mathrm{C}=\mathrm{O}$, $\mathrm{C}=\mathrm{O}$, and $\mathrm{C}-\mathrm{O}(\mathrm{O}-\mathrm{C}-\mathrm{O})$ existed on the surface. It was suggested that the dangling bond on the DLC surface bonded with oxygen when the coating of DLC was completed, and the chamber was opened to the atmosphere and it was terminated.

Table 3 shows the composition ratio obtained before and after the plasma treatment. The $\mathrm{O}_{2}$ plasma showed increases in the ratio of $\mathrm{C}=\mathrm{O}$, and $\mathrm{O}=\mathrm{C}-\mathrm{O}$ bonds. The $\mathrm{NH}_{3}$ plasma showed increases in the ratio of $\mathrm{C}-\mathrm{N}$ bond. Next, the mRNA expressions of Runx2 and type I collagen in MC3T3-E1 cells cultured on pure Ti of the control or three kinds of DLC with 

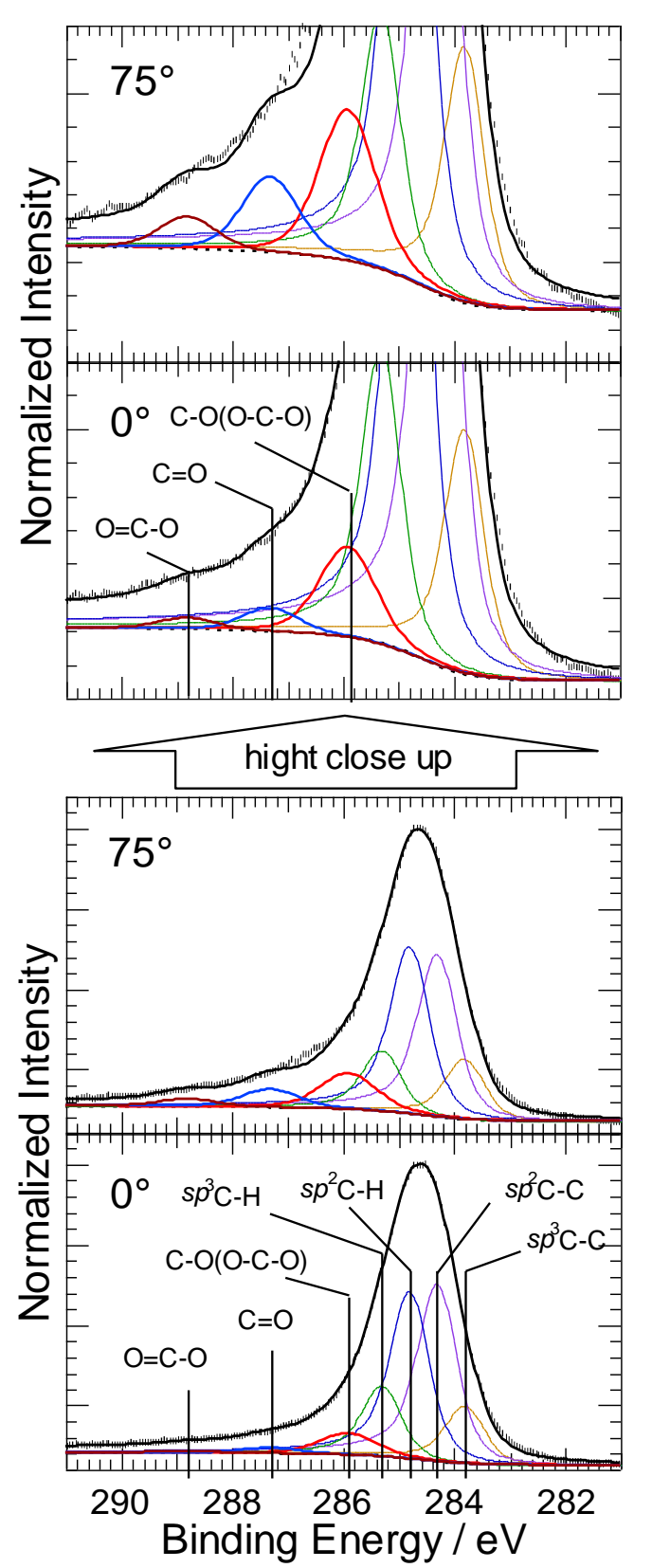

Fig. 2 The C1s spectra of untreated DLC used to analyze by the angle-resolved XPS method.

\begin{tabular}{|c|c|c|c|c|c|}
\hline & \multicolumn{5}{|c|}{ composition ratio } \\
\hline & $\begin{array}{c}\text { C-O } \\
(0-C-0)\end{array}$ & $C=0$ & $\mathrm{O}=\mathrm{C}-\mathrm{O}$ & C-N & $(\mathrm{C}-\mathrm{C}+\mathrm{C}-\mathrm{H})$ \\
\hline \begin{tabular}{|l|l|} 
No.1 & DLC(Untreated) \\
\end{tabular} & 0.06 & 0.02 & $>0.007$ & - & 0.91 \\
\hline \begin{tabular}{|l|ll|} 
No.2 & $\mathrm{O}_{2}$ & Plasma \\
\end{tabular} & 0.07 & 0.04 & 0.04 & - & 0.86 \\
\hline \begin{tabular}{|l|ll}
$\mathrm{No} 3$ & $\mathrm{NH}_{3}$ & Plasma \\
\end{tabular} & 0.03 & 0.02 & $>0.005$ & 0.15 & 0.79 \\
\hline
\end{tabular}

Table 3 Composition ratio of functionalized DLC by plasma surface treatment.

different composition ratio of the functional group element (No.1, No.2, and No.3) were examined.
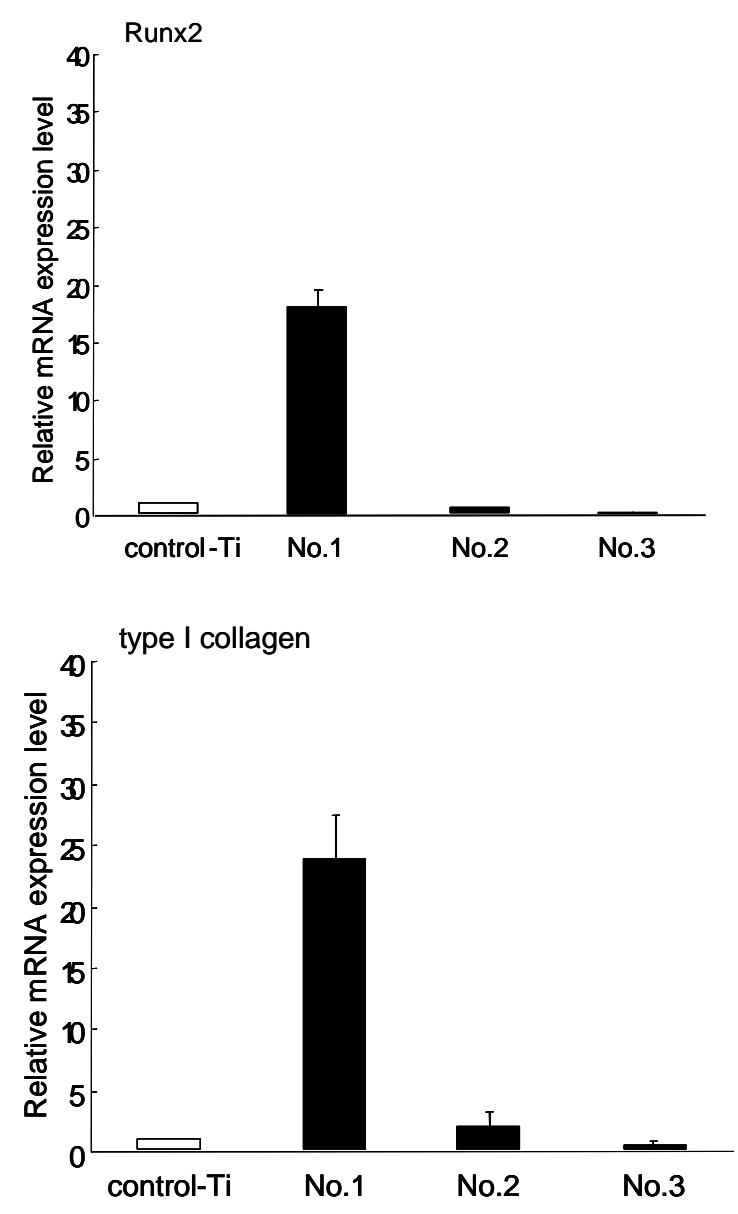

Fig.3 Effects of the DLC with different composition ratio of the functional group element on the titanium surface on the expression levels of dependent on mRNAs for Runx2 and type I collagen in MC3T3 E1 cells.

Fig. 3 shows the level of the mRNA expression of Runx 2 and type I collagen about control-Ti and DLC. The mRNA expressions of Runx2 and type I collagen in MC3T3-E1 cells cultured on sample of No.1 was about eighteen and twenty-four times, as compared those cultured on pure $\mathrm{Ti}$, respectively (ANOVA, $\mathrm{p}<0.01)$. On the other hand, these expressions in MC3T3-E1 on the sample of No.2 and No.3 were almost the same as those on pure $\mathrm{Ti}$ (ANOVA, $\mathrm{p}>0.05$ ). It was suggested that the level of the osteoblast differentiation might be dependent on the composition ratio of the surface functional group in DLC.

\section{Conclusion}

The effect of DLC thin films to introduce a functional group into surface using the plasma surface treatment technology on the expressions 
of Runx2 and type I collagen known as the markers for osteoblast differentiation was examined in the present study. A difference in differentiation marker appearance was obtained in the outcome of an experiment depending on the amount of functional groups introduced into the surface of DLC. As a result, the possibility of controlling the differentiation of osteoblast by optimizing the composition ratio of functional groups on the surface of DLC was suggested.

\section{Acknowledgements}

The result of the actual experiment was achieved by the cooperation of the regional innovation creation research and development business program of the Ministry of Economy, Trade and Industry in Japan.

\section{References}

1. T. Nakatani, K. Okamoto, A. Araki, T. Washimi, New Diamond and Frontier Carbon Technology, 16 (2006) 187.

2. C. Weissmantel, K. Bewilogua, K. Breuer, D. Dietrich, U. Ebersbach, H. J. Erler, B. Rau and G. Reisse, Thin Solid Films, 96 (1996) 31 .

3. D. P. Maguire, Diamond and Related materials, 14 (2005) 1277.

4. B. Balram, et al., Catheterization and Cardiovascular Interventions, 67 (2006) 698.

5. A. Shirakura, M. Nakaya, Y. Koga, H. Kodama, T. Hasebe and T. Suzuki, Thin Solid Films, 494 (2006) 84.

6. T. Hasebe, A. Kamijo, A. Hotta, K. Takahashi, T. Suzuki, Chemistry and Chemical Industry, 59 (2006) 1064.

7. R. Hauert, Tribology International, 37 (2004) 991.

8. R. Hauert, Diamond and Related Materials, 12 (2003) 583.

9. M. I. Jones, I. R. McColl, D. M. Grant, K. G. Parker, T. L. Parkar, J. Biomedical Material Reserch, 52 (2000) 413.
10. N. Nurdin, P. Francois, Y. Mugnier, J. Krumeich, M. Moret, B. O. Aronsson and P. Descounts, European Cells and Materials, 5 (2003) 17.

11. D. Antoniucci, et al., Am. J. Cardiol., 85 (2000) 821.

12. T. Nakatani, K. Okamoto, I. Omura, S. Yamashita, J. Photopolymer Science and Technology, 20 (2007) 221.

13. T. Nakatani, K. Okamoto, I. Omura, S. Yamashita, New Diamond and Frontier Carbon Technology, 17 (2007) 289.

14. K. Okamoto, T. Nakatani, S. Yamashita, S. Takabayashi, T. Takahagi, Surface and Coating Technology, 202 (2008) 5750.

15. T. Nakatani, K. Okamoto, Y. Nitta, A. Mochizuki, H. Hoshi and A. Homma, $J$. Photopolymer Science and Technology, 21 (2008) 225.

16. Y. Nitta, K. Okamoto, T. Nakatani, H. Hoshi, A. Homma, E. Tatsumi and Y. Taenaka, Diamond and Related Materials, 17 (2008) 1972.

17. L. Boyapati, H. Wang, Implant Dentistry, 15 (2006) 160.

17. W. S. Pietrzak, B. L. Epply, J. of Craniofacal Surgery, 16 (2005) 1043.

18. S. Takabatashi, K. motomitsu, T. takahagi, A. terayama, K. okamoto and T, nakatani, $J$. Applied Physics, 101 (2007) 103542.

19. S. Takabayashi, K. Okamoto, K. Motomitsu, A. Terayama, T. Nakatani, H. Sakaue, H. Suzuki, T. Takahagi, Applied Surface Science, 254 (2008) 2666.

20. S. Takabayashi, K. Okamoto, T. Nakatani, H. Sakaue, T. Takahagi, TANSO, 235 (2008) 280. (in Japanese)

21. S. Makihira, Y. Mine, H. Nikawa, T. Shuto, E. Kosaka, M. Sugiyama, R. Hosokawa. J Mater Sci Mater Med. 21 (2010) 647.

22. Y. Mine, S. Makihira, H. Nikawa, H. Murata, R. Hosokawa, A. Hiyama, S. Mimura. J Prosthodont Res. 54 (2010) 1. 